\title{
C-Met Inhibitor MK2461
}

National Cancer Institute

\section{Source}

National Cancer Institute. c-Met Inhibitor MK2461. NCI Thesaurus. Code C90591.

A selective small-molecule inhibitor of the proto-oncogene c-Met with potential antineoplastic activity. c-Met inhibitor MK2461 preferentially inhibits activated c-Met in an ATP-competitive manner, thereby inhibiting its tyrosine kinase activity, which may inhibit c-Met signaling and result in cell growth inhibition in tumors that overexpress c-Met. cMet, encoding the hepatocyte growth factor receptor (HGFR) tyrosine kinase, plays an important role in tumor cell proliferation and has been shown to be overexpressed or mutated in a variety of cancers. 